\title{
Simulation of Water Exchange in Enclosed Water Bodies
}

\author{
Erdal Özhan ${ }^{1}$ and Lale Balas ${ }^{2}$ \\ ${ }^{1}$ Middle East Technical University, Civil Engineering Department, Coastal Engineering \\ Laboratory, 06531 Ankara, Turkey \\ ozhan@metu.edu.tr \\ ${ }^{2}$ Gazi University, Faculty of Engineering and Architecture, Civil Engineering Department, \\ 06570 Ankara, Turkey \\ lalebal@gazi.edu.tr.
}

\begin{abstract}
A 0-D (box type) mathematical flushing model and a threedimensional baroclinic numerical model have been presented that are used to simulate transport processes in coastal waters. The numerical model consists of hydrodynamic, transport and turbulence model components. In the hydrodynamic model component, the Navier-Stokes equations are solved with the Boussinesq approximation. The transport model component consists of the pollutant transport model and the water temperature and salinity transport models. In this component, the three dimensional convective diffusion equations are solved for each of the three quantities. In the turbulence model, a two-equation $k-\varepsilon$ formulation is solved to calculate the kinetic energy of the turbulence and its rate of dissipation, which provides the variable vertical turbulent eddy viscosity. Horizontal eddy viscosity can be simulated by the Smagorinsky algebraic sub-grid scale turbulence model. The solution method is a composite finite differencefinite element method. In the horizontal plane finite difference approximations and in the vertical plane finite element shape functions are used. The governing equations are solved implicitly in the Cartesian coordinate system. The horizontal mesh sizes can be variable. To increase the vertical resolution, grid clustering can be applied. In the treatment of coastal land boundaries, the flooding and drying processes can be considered. The developed numerical model predictions are verified by the hydraulic model studies conducted on the forced flushing of marinas in enclosed seas.
\end{abstract}

\section{Introduction}

Tide, wind, fresh water inflow, gravitation, macro instabilities and waves are the six basic mechanisms which produce motion and mixing in water bodies. Along Turkish shores the tidal ranges are typically from $0.1 \mathrm{~m}$. to $0.3 \mathrm{~m}$., which are quite low values for sufficient levels of water exchanges. Therefore, lower frequency motions due to wind or fresh water inflow are dominant throughout the Turkish shores. Gravitational movement superposes over the effects of wind and the fresh water inflow.

In recent years, there have been a lot of studies performed on 0-Dimensional (box type water exchange, 2-Dimensional (depth averaged) and 3-Dimensional (full picture) transport models. 0-D numerical models do not pay attention to the internal hydraulics within the water body [1],[2]. The most simplifying assumption of the model 
is the complete and uniform mixing of the pollutant at any time with water present in the water body. 2-D numerical models, where the flow is depth averaged, can be successfully used to simulate circulation, when density differences do not play a significant role. Tidal circulation in coastal areas is a typical example. Such models are also used for designing optimal layout of marinas to assure sufficient flushing. The use of 3-D models is unavoidable in all cases where the influence of density distribution, or vertical velocity variations can not be neglected. Inflow of lower salinity river plumes into coastal sea is a typical example, but often also in the simulation of tidal flows the influence of density differences can not be neglected. In cases of wind driven flows in smaller areas near the shore, the depth-averaged 2-D models can not simulate the 3-D character of the flow. With wind-driven flows the density stratification causes an additional effect: an important diminishing of the shear stress between the horizontal layers, the consequence being that the surface layer circulation can differ considerably from the depth averaged circulation. Strong stratification in water bodies usually also demands the use of 3-D models [3]. In this paper a 0-D flushing model proposed for enclosed water bodies and a 3-D fully implicit transport model have been presented.

\section{Zero Dimensional, Box Type Flushing Model}

A non-conservative substance with a first order decay reaction is considered. Its concentration is $\mathrm{C}_{\mathrm{o}}$ at the start of the computations. The intrusion of the pollutant into the coastal water body continues at a constant rate $\mathrm{P}$. As the model is zero dimensional, the pollutant concentration is assumed not to vary spatially. This requires complete mixing inside the water body at all times. The model equation, stating the conservation of the pollutant mass in the enclosed water body is written as [1],[2],[4]:

$$
\frac{\mathrm{dC}}{\mathrm{dt}}=-\left(\mathrm{k}+\frac{\mathrm{Q}}{\mathrm{V}}\right) \mathrm{C}+\frac{\mathrm{P}}{\mathrm{V}}
$$

in which, C: the instantaneous pollutant concentration; k: decay coefficient; Q: entering discharge; V: water volume inside the marina.

When the flushing is due to the tidal discharge alone, the bulk conservation equation becomes:

$$
\begin{gathered}
\frac{\mathrm{dC}}{\mathrm{dt}}=-\mathrm{kC}+\frac{\mathrm{P}}{\mathrm{V}} \text { for } \mathrm{nT} \leq \mathrm{t} \leq\left(\mathrm{n}+\frac{1}{2}\right) \mathrm{T}(\text { ebb tide }) \\
\frac{\mathrm{dC}}{\mathrm{dt}}=-\left(\mathrm{k}+\frac{\mathrm{Q}}{\mathrm{V}}\right) \mathrm{C}+\frac{\mathrm{P}}{\mathrm{V}} \text { for }\left(\mathrm{n}+\frac{1}{2}\right) \mathrm{T} \leq \mathrm{t} \leq(\mathrm{n}+1) \mathrm{T} \text { (flood tide) }
\end{gathered}
$$

in which, T: tidal period, $\mathrm{n}$ : a positive integer ("zero" included) and $\mathrm{t}=0, \mathrm{~T}, 2 \mathrm{~T}, \ldots$, are the times of mean high tide level (i.e. the onset of the ebb tide). The timely variations of the tidal discharge $\mathrm{Q}$ and the water volume $\mathrm{V}$ are used as:

$$
\begin{gathered}
\mathrm{Q}=-\frac{1}{2} \mathrm{~A}_{\mathrm{S}} \mathrm{R} \mathrm{w} \sin (\mathrm{wt}) \\
\mathrm{V}=\mathrm{V}_{\mathrm{S}}+\frac{1}{2} \mathrm{~A}_{\mathrm{S}} \mathrm{R} \cos (\mathrm{wt})
\end{gathered}
$$

where, $\mathrm{A}_{\mathrm{s}}$ : Surface area at mean sea level; $\mathrm{V}_{\mathrm{s}}$ : Mean tide level volume; R: Tidal range (from mean low level to mean high level) and w: $2 \pi / \mathrm{T}$. 
The solution giving the pollutant concentration at the time of high tide after the $\mathrm{n}$ - th tidal cycle is:

$$
\mathrm{C}_{\mathrm{n}}=\mathrm{a}^{\mathrm{n}} \mathrm{C}_{\mathrm{O}}+\frac{\left.\mathrm{b}(1-\mathrm{a})^{\mathrm{n}}\right)}{1-\mathrm{a}} \mathrm{C}_{\mathrm{a}}
$$

in which,

$$
\begin{aligned}
& \mathrm{a}=\frac{\mathrm{M}-1}{\mathrm{M}+1} \mathrm{e}^{-\mathrm{kT}} \\
& \mathrm{b}=\frac{2}{\mathrm{kT}}\left[\frac{\mathrm{M}}{\mathrm{M}+1}\left(1-\mathrm{e}^{-\mathrm{k} \frac{\mathrm{T}}{2}}\right)-\mathrm{a}\left(1-\frac{\mathrm{k}^{2}}{\mathrm{M}\left(\mathrm{k}^{2}+\mathrm{w}^{2}\right)}\right)+\mathrm{ae}^{\mathrm{k} \frac{\mathrm{T}}{2}}\left(1+\frac{\mathrm{k}^{2}}{\mathrm{M}\left(\mathrm{k}^{2}+\mathrm{w}^{2}\right)}\right)\right] \\
& \mathrm{M}=\frac{2 \mathrm{~V}_{\mathrm{S}}}{\mathrm{A}_{\mathrm{S}} \mathrm{R}}=2 \frac{\overline{\mathrm{h}}}{\mathrm{R}} ; \mathrm{C}_{\mathrm{a}}=\frac{\mathrm{PT}}{2 \mathrm{~V}_{\mathrm{S}}}
\end{aligned}
$$

where, h: mean water depth, M: flushing parameter.

If the substance is conservative then $\mathrm{k}=0$ and equation for $\mathrm{C}_{\mathrm{n}}$ still holds if the parameters $\mathrm{a}$ and $\mathrm{b}$ are redefined as:

$$
a=\frac{M-1}{M+1} ; b=\frac{M\left(1+\frac{M-1}{M+1}\right)}{M+1}
$$

The zero dimensional model presented above is applied to Ölüdeniz Lagoon. Ölüdeniz Lagoon is an example of choked lagoons [8]. The lagoon is connected to the sea by a single narrow and shallow channel. This entrance channel serves as a dynamic filter and tidal currents are damped out. In the Mediterranean Sea tidal ranges are typically in the order of 0.2 to 0.3 meters. Despite the smallness of the tidal amplitude, a considerable level of flushing is induced by the tidal motion [6].

Flushing of Ölüdeniz lagoon is controlled primarily by the two processes: firstly the tidal action and secondly the wind driven currents. Density driven currents are rather weak compared to the tide and wind induced currents [7]. Tidal motion at the site of Ölüdeniz Lagoon is typically semi-diurnal. The mean tidal range is about $0.15 \mathrm{~m}$ and the tidal period is 12 hours and 25 minutes. Lagoon is rather deep with a mean water depth of $17 \mathrm{~m}$. In the middle of the lagoon, the water depth reaches about $40 \mathrm{~m}$.

The model provides a quick assessment of the degree of tidal flushing to be expected. The mean depth of the lagoon is $17 \mathrm{~m}$. and the surface area is about 406000 $m^{2}$. The tidal motion at the site of Ölüdeniz Lagoon is semi-diurnal type. The mean tidal range is about $0.15 \mathrm{~m}$., which is typical around the Turkish Mediterranean coastline. The flushing parameter has a value of 227. The $C_{n} / C_{o}$ ratios are computed for a conservative pollutant and results are plotted in Figure 1. This figure depicts the situation that if no pollutant is introduced into the lagoon (i.e. for $C_{d} / C_{o}=0$ ), it takes 261days for the pollutant amount in the lagoon to be flushed out by the tidal currents alone up to level of $99 \%$, i.e. to have the value of $C_{n} / C_{o}=1 \%$. If the pollutant continues 
entering the lagoon waters, the flushing period of the lagoon gets much longer. Furthermore, it is computed that $C_{n=} C_{o}$ for all times if the pollutant addition rate is such that $C_{a} / C_{o}=0.0044$. As it is observed from Figure 1, the cleansing of the lagoon can not be realized at all if $C_{d} / C_{o}=0$.

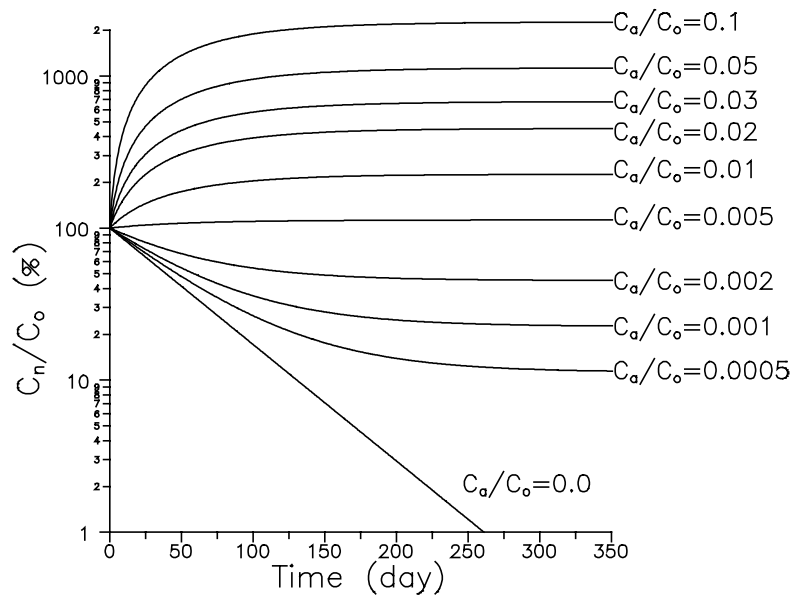

Fig. 1. The changes of pollutant concentration with time for various rates of pollutant addition.

\section{Three Dimensional Numerical Model}

An unsteady three-dimensional baroclinic circulation model (HIDROTAM3) has been developed to simulate the transport processes in coastal water bodies [3]. The model predictions were verified by using several experimental and analytical results published in the literature and its successful use for a variety of real life cases was demonstrated [3][8][10].

The governing hydrodynamic equations in the three dimensional Cartesian coordinate system are as follows [3]:

$$
\frac{\partial \mathrm{u}}{\partial \mathrm{x}}+\frac{\partial \mathrm{v}}{\partial \mathrm{y}}+\frac{\partial \mathrm{w}}{\partial \mathrm{z}}=0
$$

The momentum equations in the orthogonal horizontal directions $\mathrm{x}$ and $\mathrm{y}$ :

$$
\begin{aligned}
& \frac{\partial u}{\partial t}+u \frac{\partial u}{\partial x}+v \frac{\partial u}{\partial y}+w \frac{\partial u}{\partial z}=f v-\frac{1}{\rho_{o}} \frac{\partial p}{\partial x}+2 \frac{\partial}{\partial x}\left(v_{x} \frac{\partial u}{\partial x}\right)+\frac{\partial}{\partial y}\left(v_{y}\left(\frac{\partial u}{\partial y}+\frac{\partial v}{\partial x}\right)\right)+\frac{\partial}{\partial z}\left(v_{z} \frac{\partial u}{\partial z}\right) \\
& \frac{\partial v}{\partial t}+u \frac{\partial v}{\partial x}+v \frac{\partial v}{\partial y}+w \frac{\partial v}{\partial z}=-f u-\frac{1}{\rho_{o}} \frac{\partial p}{\partial y}+2 \frac{\partial}{\partial y}\left(v_{y} \frac{\partial v}{\partial y}\right)+\frac{\partial}{\partial x}\left(v_{x}\left(\frac{\partial v}{\partial x}+\frac{\partial u}{\partial y}\right)\right)+\frac{\partial}{\partial z}\left(v_{z} \frac{\partial v}{\partial z}\right)
\end{aligned}
$$

The momentum equation in the vertical direction $\mathrm{z}$ :

$$
\frac{\partial w}{\partial t}+u \frac{\partial w}{\partial x}+v \frac{\partial w}{\partial y}+w \frac{\partial w}{\partial z}=-\frac{1}{\rho_{0}} \frac{\partial p}{\partial z}-g+\frac{\partial}{\partial y}\left(v_{y}\left(\frac{\partial w}{\partial y}+\frac{\partial v}{\partial z}\right)\right)+\frac{\partial}{\partial x}\left(v_{X}\left(\frac{\partial w}{\partial x}+\frac{\partial u}{\partial z}\right)\right)+\frac{\partial}{\partial z}\left(v_{z} \frac{\partial w}{\partial z}\right)
$$


where, $\mathrm{x}, \mathrm{y}$ : Horizontal coordinates; $\mathrm{z}$ : Vertical coordinate; t: Time; u,v,w: Velocity components in $\mathrm{x}, \mathrm{y}, \mathrm{z}$ directions at any grid locations in space; $\mathrm{v}_{\mathrm{x}}, \mathrm{v}_{\mathrm{y}}, \mathrm{v}_{\mathrm{z}}$ : Eddy viscosity coefficients in $\mathrm{x}, \mathrm{y}$ and $\mathrm{z}$ directions respectively; f: Corriolis coefficient; $\rho(\mathrm{x}, \mathrm{y}, \mathrm{z}, \mathrm{t})$ : In situ water density; $\rho_{0}$ : Reference density; g: Gravitational acceleration; p: Pressure.

The temperature and salinity variations are calculated by solving the three dimensional convection-diffusion equation which is written as:

$$
\frac{\partial Q}{\partial t}+u \frac{\partial Q}{\partial x}+v \frac{\partial Q}{\partial y}+w \frac{\partial Q}{\partial z}=\frac{\partial}{\partial x}\left(D_{x} \frac{\partial Q}{\partial x}\right)+\frac{\partial}{\partial x}\left(D_{y} \frac{\partial Q}{\partial y}\right)+\frac{\partial}{\partial z}\left(D_{z} \frac{\partial Q}{\partial z}\right)
$$

where, $D_{x}, D_{y}$ and $D_{z}$ : Turbulent diffusion coefficient in $x, y$ and $z$ directions respectively; Q: Temperature $(\mathrm{T})$ or salinity $(\mathrm{S})$. The conservation equation for a pollutant constituent is:

$\frac{\partial \mathrm{C}}{\partial \mathrm{t}}+\mathrm{u} \frac{\partial \mathrm{C}}{\partial \mathrm{x}}+\mathrm{v} \frac{\partial \mathrm{C}}{\partial \mathrm{y}}+\mathrm{w} \frac{\partial \mathrm{C}}{\partial \mathrm{z}}=\frac{\partial}{\partial \mathrm{x}}\left(\mathrm{D}_{\mathrm{x}} \frac{\partial \mathrm{C}}{\partial \mathrm{x}}\right)+\frac{\partial}{\partial \mathrm{x}}\left(\mathrm{D}_{\mathrm{y}} \frac{\partial \mathrm{C}}{\partial \mathrm{y}}\right)+\frac{\partial}{\partial \mathrm{z}}\left(\mathrm{D}_{\mathrm{z}} \frac{\partial \mathrm{C}}{\partial \mathrm{z}}\right)-\mathrm{k}_{\mathrm{p}} \mathrm{C}$

where, C: Pollutant concentration; $\mathrm{k}_{\mathrm{p}}$ : Decay rate of the pollutant; $\mathrm{D}_{\mathrm{x}}, \mathrm{D}_{\mathrm{y}}$ and $\mathrm{D}_{\mathrm{z}}$ : Turbulent diffusion coefficient in $\mathrm{x}, \mathrm{y}$ and $\mathrm{z}$ directions respectively.

The two-equation $k-\varepsilon$ turbulence model is used for turbulence modeling. The model equations for the kinetic energy and dissipation of the kinetic energy are:

$$
\begin{gathered}
\frac{\partial \mathrm{k}}{\partial \mathrm{t}}+\mathrm{u} \frac{\partial \mathrm{k}}{\partial \mathrm{x}}+\mathrm{v} \frac{\partial \mathrm{k}}{\partial \mathrm{y}}+\mathrm{w} \frac{\partial \mathrm{k}}{\partial \mathrm{z}}=\frac{\partial}{\partial \mathrm{z}}\left(\frac{v_{\mathrm{z}}}{\sigma_{\mathrm{k}}} \frac{\partial \mathrm{k}}{\partial \mathrm{z}}\right)+\mathrm{P}+\mathrm{B}-\varepsilon+\mathrm{F}_{\mathrm{k}} \\
\frac{\partial \varepsilon}{\partial \mathrm{t}}+\mathrm{u} \frac{\partial \varepsilon}{\partial \mathrm{x}}+\mathrm{v} \frac{\partial \varepsilon}{\partial \mathrm{y}}+\mathrm{w} \frac{\partial \varepsilon}{\partial \mathrm{z}}=\frac{\partial}{\partial \mathrm{z}}\left(\frac{\mathrm{v}_{\mathrm{z}}}{\sigma_{\varepsilon}} \frac{\partial \varepsilon}{\partial \mathrm{z}}\right)+\mathrm{c}_{1 \varepsilon} \frac{\varepsilon}{\mathrm{k}}\left(\mathrm{P}+\mathrm{c}_{3 \varepsilon} \mathrm{B}\right)-\mathrm{c}_{2 \varepsilon} \frac{\varepsilon^{2}}{\mathrm{k}}+\mathrm{F}_{\varepsilon}
\end{gathered}
$$

where, k: Kinetic energy; $\varepsilon$ : Rate of dissipation of kinetic energy; $F_{k}$ : Horizontal diffusion terms for the kinetic energy; $F_{\varepsilon}$ : Horizontal diffusion terms for the dissipation of kinetic energy; P: Stress production of the kinetic energy; B: Buoyancy production of the kinetic energy.The stress production of the kinetic energy is defined by:

$$
P=v_{h}\left[2\left(\frac{\partial u}{\partial x}\right)^{2}+2\left(\frac{\partial v}{\partial y}\right)^{2}+\left(\frac{\partial u}{\partial y}+\frac{\partial v}{\partial x}\right)^{2}\right]+v_{z}\left[\left(\frac{\partial u}{\partial z}\right)^{2}+\left(\frac{\partial v}{\partial z}\right)^{2}\right]
$$

where, $v_{\mathrm{h}}$ is the horizontal eddy viscosity and $\mathrm{u}, \mathrm{v}$ are the horizontal water particle velocities in $\mathrm{x}$ and $\mathrm{y}$ directions respectively.

The vertical eddy viscosity is calculated by:

$$
v_{\mathrm{z}}=\mathrm{C}_{\mu} \frac{\mathrm{k}^{2}}{\varepsilon}
$$

To account for large-scale turbulence generated by the horizontal shear, horizontal eddy viscosity can be simulated by the Smagorinsky algebraic sub-grid scale turbulence model.

\section{Model Application to a Laboratory Flume}

The predictions of transport model component are compared with the results of a laboratory model harbor study using dye tracer [9]. The model harbor was set to be a 
square, with prototype dimensions of $432 \mathrm{mx} 432 \mathrm{~m}$. The tidal range was $0.1 \mathrm{~m}$ and tidal period was $708 \mathrm{~s}$. Dye was injected into the enclosed basin to provide an initial uniform concentration across the basin. Dye experimental results and numerical model predictions at low tide for the first cycle and for the second cycle are presented in Figure (2) and in Figure (3) respectively.

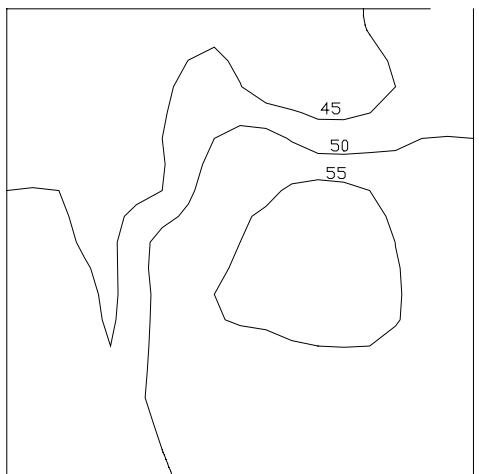

(a)

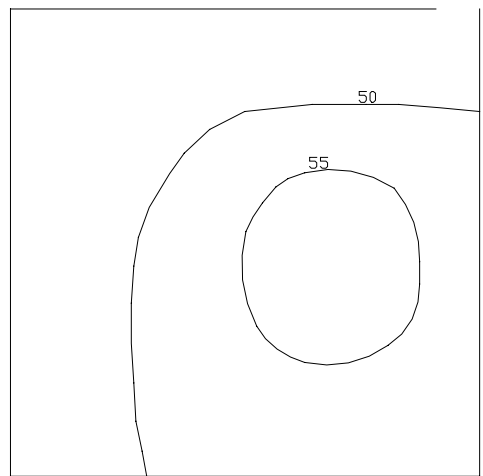

(b)

Fig. 2. a) Dye experimental results at low tide for the first tidal cycle, b) Numerical simulations at low tide for the first tidal cycle (\% of initial concentration contours).

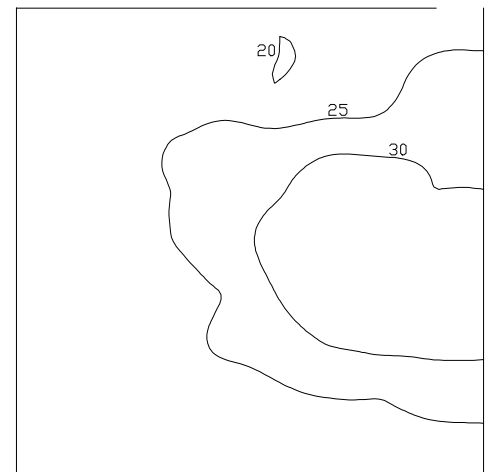

(a)

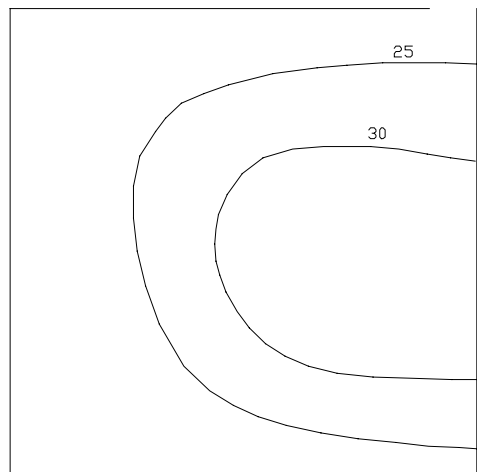

(b)

Fig. 3.. a) Dye experimental results at low tide for the second tidal cycle, b) Numerical simulations at low tide for the second tidal cycle (\% of initial concentration contours).

Centroidal distribution is well predicted by the model. However, close to the harbor entrance, the predicted concentrations are about $17 \%$ higher than the measurements. The main reason for this may be the estimation of rather weak flow and small eddies close to the open boundary. Overall the numerical predictions are in good agreement with the experimental results. 


\section{Forced Flushing of Marinas in Enclosed Seas}

Construction of a marina disturbs the natural flow patterns and normally deteriorates the water quality in and around the project site [3]. Water enclosed in a marina basin is normally tranquil and has a restricted contact with the outside sea. Water exchange takes place only through the entrance. The cross sectional area of the entrance is often small and the exchange is low especially in areas where the tidal range is small. Water, which enters into the basin, can not freely circulate. Limited water circulation may result in poor water quality levels in the marina. It is often necessary to apply some special design features to enhance flushing of marinas. The use of a "MorningGlory Spillway" like structure to pump out water from the marina for improving the flushing performance is investigated. A physical model study was performed in the Coastal Engineering Laboratory of the Middle East Technical University. The measured velocities in the physical model at the grid points neighboring the intake are used as the boundary conditions in the mathematical model. The length scale of the model was $1 / 50$. The length and width of the rectangular model marina basin were $5.80 \mathrm{~m}$. and $2.8 \mathrm{~m}$., respectively. The average water depth was $0.2 \mathrm{~m}$. Using the length scale of $1 / 50$, these dimensions correspond to a prototype marina of $290 \mathrm{~m}$ by $140 \mathrm{~m}$., with a water depth of $10 \mathrm{~m}$. Surface water was withdrawn from the marina by installing a structure similar to the morning-glory spillway. The water taken from the basin was pumped into the open sea. The discharge point was selected so that, the motion resulting from the pumped water does not affect the circulation in the basin. Velocity measurements were taken with a 'Minilab SD-12' microscale 3-axis ultrasonic current meter. The morning glory shaped intake structure was placed at various locations in the basin. Two of them, which are at the corners, are presented in this paper. The choice of the corner locations is due to the concern for affecting the maneuvering space of the crafts inside the marina. The grid system used has a square mesh size of $10 \times 10 \mathrm{~m}$. The vertical eddy viscosity is calculated by the k- $\varepsilon$ model and horizontal eddy viscosities are predicted by the sub-grid scale turbulence model. At $\mathrm{t}=0$, the pump is started, so that the water begins to flow in the intake, whereas the remaining part of the water body is assumed to be at rest and the water surface is assumed to be horizontal. The land boundaries are taken as fixed boundaries. Velocities measured in the physical model at the grid points neighboring the intake are used as the boundary conditions of the intake location in the mathematical model. Steady state conditions are reached approximately 1.5 hours after the start of pumping. The paths followed by the floats in the physical model are compared with the results obtained from the mathematical model in Figures (4-5). The velocity distributions at the surface layer as obtained from the mathematical model are also shown. The average velocities along the paths followed by the floats in both physical and mathematical models are compared in Table (1). In Case I, the intake structure is placed on the right end corner of the marina $(135 \mathrm{~m}$. x $285 \mathrm{~m}$.). The best agreement is obtained for the path followed by the float number 2 released at location $(100 \mathrm{~m}$. $\mathrm{x} 0$ m.) with an average velocity relative error of $0.55 \%$. The highest relative error in the average velocity is calculated as $24.4 \%$ for the float number 7 which released at location $(30 \mathrm{~m}$. x $10 \mathrm{~m}$.). For this path, the velocities predicted by the numerical model are less than the velocities observed in the physical model. 
Table 1. Average velocities along the float paths.

\begin{tabular}{|c|c|c|c|c|c|}
\hline \multirow[t]{2}{*}{$\begin{array}{c}\text { Float } \\
\text { number }\end{array}$} & \multirow[t]{2}{*}{$\begin{array}{l}\text { Release } \\
\text { location } \\
(\mathrm{x}, \mathrm{y}) \text { in } \mathrm{m} .\end{array}$} & \multicolumn{2}{|c|}{$\begin{array}{c}\text { Physical model } \\
\text { average velocity }(\mathrm{cm} / \mathrm{s})\end{array}$} & \multicolumn{2}{|c|}{$\begin{array}{l}\text { Mathematical model } \\
\text { average velocity } \\
(\mathrm{cm} / \mathrm{s})\end{array}$} \\
\hline & & Case I & Case II & Case I & Case II \\
\hline 1 & $90 \times 0$ & $* *$ & 4.04 & $* *$ & 4.15 \\
\hline 2 & $100 \times 0$ & 3.64 & 5.27 & 3.66 & 4.51 \\
\hline 3 & $110 \times 0$ & 3.61 & 5.16 & 3.88 & 5.04 \\
\hline 4 & $120 \times 0$ & 3.72 & 3.88 & 3.91 & 4.01 \\
\hline 5 & $130 \times 0$ & $* *$ & $* *$ & $* *$ & $* *$ \\
\hline 6 & $70 \times 10$ & 2.24 & $* *$ & 1.98 & $* *$ \\
\hline 7 & $30 \times 10$ & 0.93 & $* *$ & 0.70 & $* *$ \\
\hline 8 & $130 \times 240$ & $* *$ & 2.72 & $* *$ & 3.51 \\
\hline
\end{tabular}

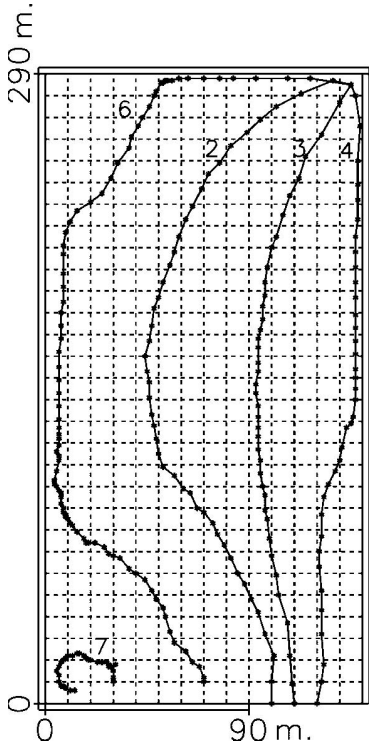

a) Physical model

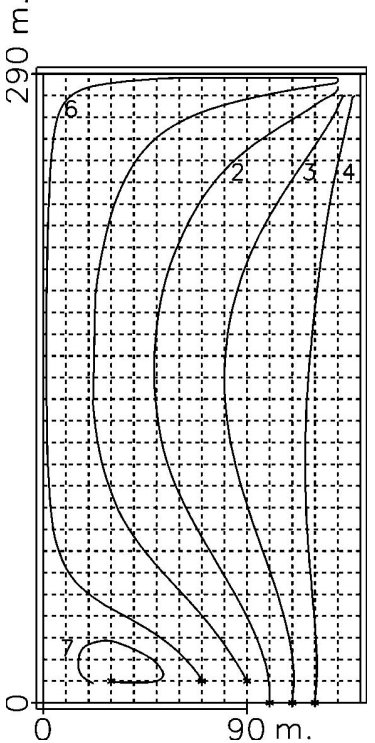

b) Numerical model

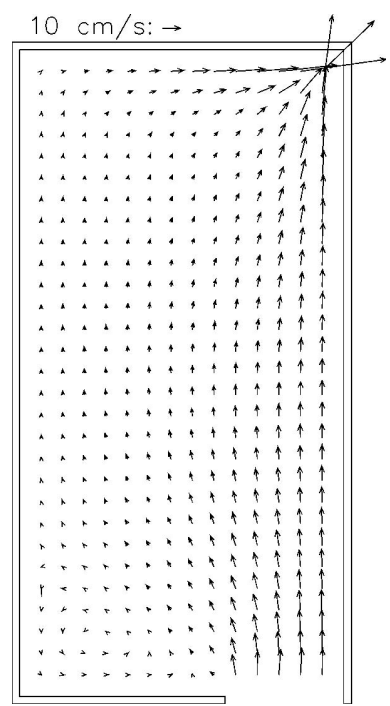

c) Numerical model

Fig. 4. Float paths and velocity distributions at the surface layer, when the morning glory is placed on the right end corner of the marina.

There is a dead zone where the released float does not move through the intake, since there occurs a gyre. Therefore, the float number 7 follows a counter clockwise elliptical route. The location of dead zone is almost the same for physical and numerical models. 


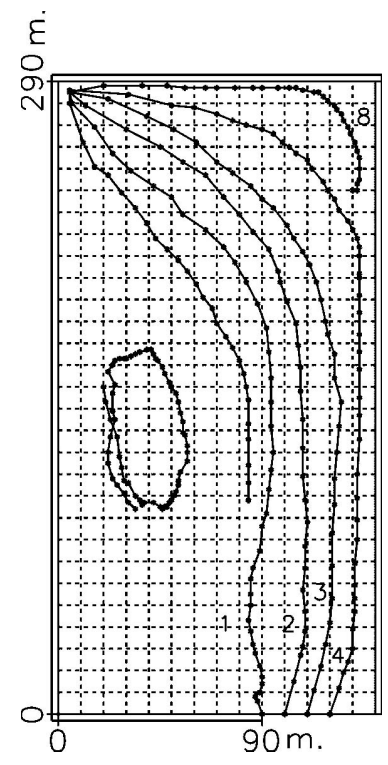

a) Physical model

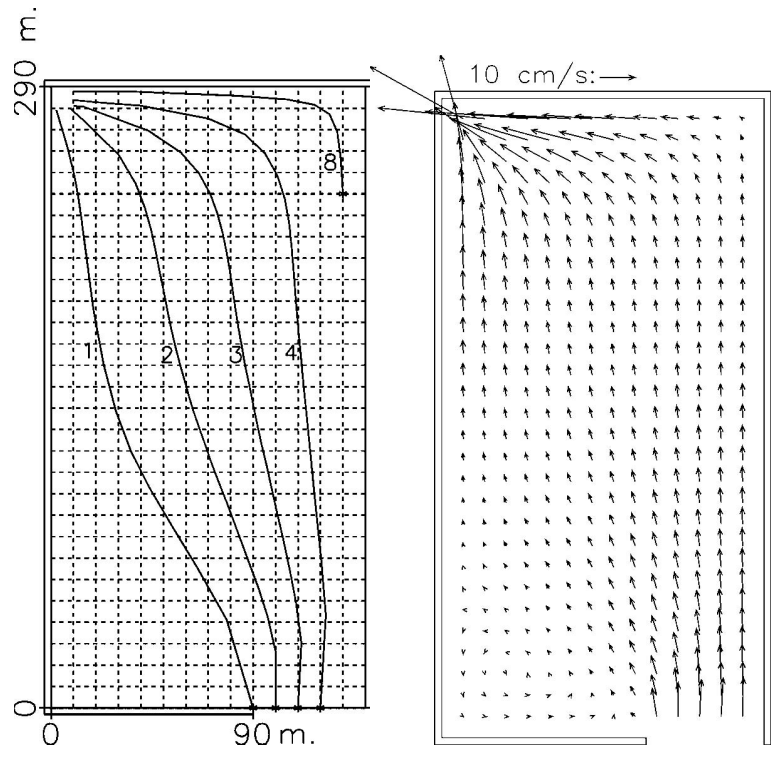

b) Numerical model

c) Numerical model

Fig. 5. Float paths and velocity distributions at the surface layer, when the morning glory is placed on the left end corner of the marina.

In Case II, the intake structure is placed on the left end corner of the marina (5 m. x $285 \mathrm{~m}$.). The closest agreement in the path trajectory is obtained for the float number 8 , which is released at location $(130 \mathrm{~m}$. x $240 \mathrm{~m}$.). However, the relative error in its average velocity is the highest, $29 \%$. In the physical model, a dead zone is observed in the left-hand side of the basin towards the middle of the y-axis. On the other hand, the dead zone predicted by the numerical model is on the left entrance corner of the basin and it occupies a rather restricted area. The pumping operation should be carried out during flood tide only to derive the greatest efficiency from such a system. The best location of the intake for removal of water and the optimum discharge rate are two crucial issues for designing such a scheme. The first question becomes especially important in the case of complex basins where the problems of "dead regions" are normally more significant. Such features have traditionally been investigated in physical models.

\section{Conclusions}

By assuming complete and uniform mixing of the pollutant at any time with the water present in the lagoon, zero dimensional model is applied to the Ölüdeniz Lagoon. This assumption is a crude assumption for the Ölüdeniz lagoon, which is rather deep. 
However the zero dimensional mathematical model provides a quick assessment of the degree of tidal flushing to be expected. It shows that flushing due to tidal motion alone is not sufficient for maintaining an acceptable water quality in the lagoon. Secondly, a three dimensional numerical model which consists of hydrodynamic, transport and turbulence model components has been presented. Three-dimensional modeling is necessary for investigating lagoon flushing due to mechanisms other than tide, such as wind and density currents. The presented three dimensional model is a valuable design tool and can be implemented in a Decision Support System. It may be used in diverse coastal applications including the prediction of natural flushing rates caused by tidal motion, wind effect, density currents or a fresh water inflow.

\section{References}

1. Özhan, E.: Flushing of Marinas with Weak Tidal Motion. In: W.R. Blain, W.R., Weber, N.B. (eds): Marinas: Planing and Feasibility. Southampton, (1989) 485-498.

2. Özhan, E.: Water Quality Improvement Measures for Marinas Subjected to Weak Tidal Motion. Proc. Second Int. Conf. on Coastal and Port Engineering in Developing Countries, COPEDEC 3, Kenya, Vol.2, (1991) 1337-1350.

3. Balas, L., Özhan, E.: An Implicit Three Dimensional Numerical Model to Simulate Transport Processes in Coastal Water Bodies, Int. Journal for Numerical Methods in Fluids, Vol. 34 (2000) 307-339.

4. Balas, L., Özhan, E.: Flushing of Ölüdeniz Lagoon, Proc. of the Joint Conference MEDCOAST'99-EMECS'99, Antalya, Turkey, Vol.3 (1999) 1873-1884.

5. Balas, L., Özhan, E.: Three Dimensional Modelling of Transport Processes in Göksu Lagoon System, Proc.of the Second International Conference on the Mediterranean Coastal Environment, MEDCOAST'95, Tarragona, Spain, Vol. 3 (1995) 1661-1672.

6. Balas, L., Özhan, E.: Three Dimensional Modelling of Transport Processes in Stratified Coastal Waters, Proc.of International Conference on Hydroinformatics, IAHR, Copenhagen, Denmark, (1998) 97-104.

7. Balas, L., Özhan, E., Öztürk C.: Three Dimensional Modelling of Hydrodynamic and Transport Processes in Ölüdeniz Lagoon. Proc. of the Third International Conference on the Mediterranean Coastal Environment, MEDCOAST'97, Qawra, Malta, Vol. 2, (1997) 10971109.

8. Balas, L., Özhan E.: Applications of a 3-D Numerical Model to Circulations in Coastal Waters, Coastal Engineering Journal, Vol. 43, No 2 (2001) 99-120.

9. Balas, L.: Simulation of Pollutant Transport in Marmaris Bay, China Ocean Engineering., Vol.15, No.4 (2001) 565-578.

10. Balas, L., Özhan, E.: Three Dimensional Modelling of Stratified Coastal Waters. Estuarine, Coastal and Shelf Science, Vol..54 (2002) 75-87. 